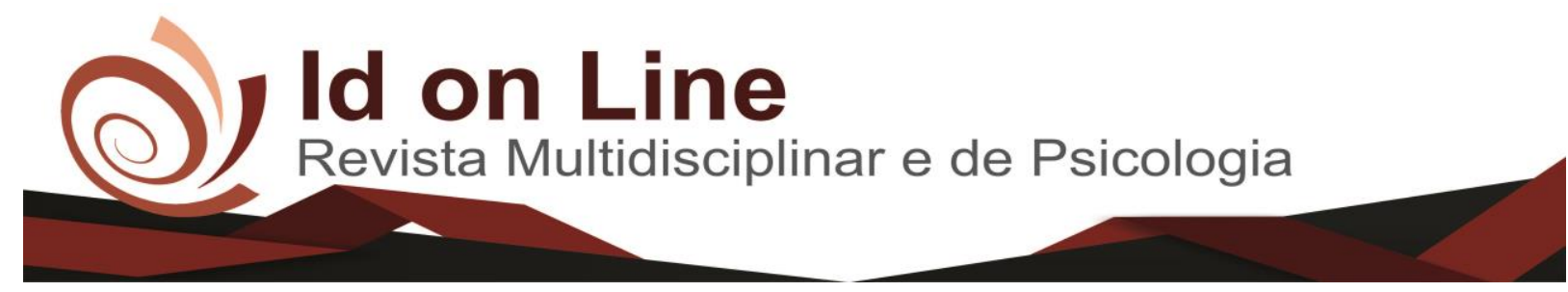

Relato de Caso

\title{
A Importância do Curso de Operações Rurais, no âmbito organizacional e pedagógico, da Companhia Independente de Policiamento Especializado - Caatinga da Polícia Militar do Estado da Bahia: Um Estudo de Caso
}

Fábio Jorge Nascimento Ferreira ${ }^{1}$; Nadjane Gonçalves De Souza ${ }^{2}$; Wilton Panta Da Silva ${ }^{3}$

Resumo: O objetivo principal deste trabalho é validar a importância do Curso de Operações Rurais, no âmbito da Polícia Militar do Estado da Bahia, enquanto pratica pedagógica-organizacional, tendo como seu principal agente, a CIPE/Caatinga, unidade responsável pela implantação do modelo de atuação operacional adotado junto às Companhias Independentes de Policiamento Especializado - CIPE's. Desenvolvido através de estudos sobre gestão de competências, processos de ensino-aprendizagem, educação corporativa, gestão de pessoas, docência, prática pedagógica e treinamento policial militar, evidenciando-se como um artigo original, e complementado com livros e pesquisas correlacionadas à realidade da profissão policial militar, o citado trabalho preocupou-se, basicamente, em realizar uma análise concisa e bastante didática, verificando a história, a realidade e a relevância da CIPE/Caatinga e, num segundo momento, o fomento gerado pela realização do VIII Curso de Operações Rurais e as suas repercussões no plano intitucional.

Palavras-chave: CIPE/Caatinga. Curso de Operações Rurais. Polícia Militar do Estado da Bahia. Prática Pedagógica. Gestao de Competências.

\section{The Importance of the Course of Rural Operations, in the organizational and pedagogical scope, of the Independent Company of Specialized Policing - Caatinga of the Military Police of the State of Bahia: A Case Study}

\begin{abstract}
The main objective of this work is to validate the importance of the Course of Rural Operations, within the scope of the Military Police of the State of Bahia, as pedagogical-organizational practice, having as its main agent, CIPE/Caatinga, unit responsible for the implementation of the model of action adopted by the Independent Specialized Policing Companies (CIPE's). Developed through studies on competence management, teaching-learning processes, corporate education, people management, teaching, pedagogical practice and military police training, evidenced as an original article, and complemented with books and research correlated to the reality of the profession military police, the aforementioned work was mainly concerned with conducting a concise and rather didactic analysis, checking the history, reality and relevance of the CIPE/Caatinga and, secondly, the encouragement generated by the accomplishment of the VIII Operations Course and its repercussions at the institutional level.
\end{abstract}

Keywords: CIPE/Caatinga. Course of Rural Operations. Military Police of the State of Bahia. Pedagogical Practice. Competence Management.

\footnotetext{
' É Oficial da PMBA, lotado na Companhia Independente de Policiamento Especializado - Caatinga (CIPE/Caatinga), Bacharel em Segurança Pública pela Universidade Estadual da Bahia (UNEB), Bacharel em Ciências Contábeis pela Faculdade Visconde de Cairu e Especialista em Gestão de Pessoas pela Universidade Maurício de Nassau. Operador Rural PMBA 130. E-mail: fjnf_@hotmail.com

${ }^{2}$ É Oficiala da PMBA, lotada no Comando de Policiamento Regional Norte (CPRN), Bacharel em Segurança Pública e Licenciada em Pedagogia pela Universidade Estadual da Bahia (UNEB), Especialista em Gestão de Recursos Humanos pela Faculdade de Ciências Aplicadas e Sociais de Petrolina. E-mail: nadjanegs@ hotmail.com.

3 É Oficial da PMBA, lotado na Companhia Independente de Policiamento Especializado - Caatinga (CIPE/Caatinga), Bacharel em Segurança Pública pela Universidade Estadual da Bahia (UNEB), Bacharelando em Direito pela Universidade Estadual da Bahia (UNEB), Coordenador do VIII Curso de Operações Rurais. Operador Rural PMBA 103. E-mail: wiltonpanta02@ gmail.com
}

246 Id on Line Rev. Mult. Psic. V.12, N. 39. 2018 - ISSN 1981-1179 Edição eletrônica em http://idonline.emnuvens.com.br/id 


\section{Introdução}

Onde for preciso, Com a maior força possível,

$O$ mais rápido que puder. (Lema da CIPE/CAATINGA)

Há dezesseis anos foi criada, no âmbito da Policia Militar do Estado da Bahia PMBA, através do Decreto Estadual N 7.926, de 18 de abril de 2001, a Companhia de Polícia de Ações em Caatinga - CPAC, atualmente com a nomenclatura de Companhia Independente de Policiamento Especializado - Caatinga (CIPE/Caatinga), com os mesmos moldes de atuação do que fora percebido com a existência da Companhia Independente de Operações e Sobrevivência na Área de Caatinga - CIOSAC, unidade operacional especializada pertencente à Polícia Militar do Estado de Pernambuco e que há anos lida com o combate à criminalidade existente no polígono da maconha e nas áreas de caatinga do sertão pernambucano.

Com vistas a conter o avanço das mesmas modalidades criminosas no perímetro baiano, haja vista a proximidade, apenas balizadas pelo rio São Francisco em algumas localidades, bem como atender às necessidades de segurança pública por parte da população sertaneja, a Polícia Militar do Estado da Bahia, de forma assertiva, trouxe a redenção ao nosso sertão baiano com implementação da CIPE/Caatinga, antes dominado por quadrilhas especializadas em plantio e tráfico de drogas, assim como em roubos a bancos e em rodovias. Tal medida ainda continua sendo validada e reforçada ao verificamos que, a partir da criação da CIPE/Caatinga, outras unidades operacionais especializadas foram criadas nos mesmos padrões, atendendo assim, a todos os biomas existentes no estado, tendo como principais resultados, a contenção do crime, a aprovação da comunidade baiana e o reconhecimento da excelência do trabalho desenvolvido.

Integrar uma unidade operacional especializada é um dos maiores méritos que o Policial Militar pode alcançar ao servir na Polícia Militar do Estado da Bahia. Esse modelo de policiamento é constituído por homens e mulheres dispostos e bem capacitados, manifestamente comprometidos com os valores institucionais e, ao mesmo tempo, com os mais refinados princípios da técnica policial-militar. Além disso, enquanto "tropa de elite", bons princípios e virtudes são tidos como nortes, tal como a disciplina, a lealdade, o senso de 
justiça e a bravura, considerados elementos indissociáveis, pois, só assim, tais homens e mulheres serão merecedores da farda que vestem e, acima de tudo, incorporar o espírito de comprometimento com o serviço policial militar.

A CIPE/Caatinga foi o embrião de um modelo de policiamento implementado pela Polícia Militar do Estado da Bahia, e graças ao seu comprometimento e exigência profissional, por vezes é tida como paradigma de atuação para outras instituições da esfera da Segurança Pública, devendo-se tributar tal know-how, sobretudo, no que se diz respeito à sua gestão, tanto nos campos administrativos e operacionais, como em sua estreita relação com a qualificação dos seus Policiais Militares, seja no provimento de cursos e treinamentos, seja no oferecimento estrutural necessário e adequado para o cumprimento das mais variadas missões designadas à tropa.

Por inúmeras vezes nos deparamos, enquanto cidadãos, com notícias envolvendo ações policiais no combate ao tráfico de drogas, narcotráfico, roubos e explosões à carrosfortes e à bancos, etc., e para nossa surpresa, infelizmente, tal fato tem se tornado deveras recorrente com o passar dos anos, especificamente, na região nordeste do país, e de forma mais pontual, no norte do Estado da Bahia, visto, inclusive, dada à sua posição limítrofe com o estado do Pernambuco, e com o famigeradamente conhecido Polígono da Maconha.

Para tal finalidade, e do ponto de vista estratégico e organizacional, no que se diz respeito às políticas de segurança pública, há o emprego da Companhia Independente de Policiamento Especializado - Caatinga, a fim de prevenir, reprimir e conter tais modalidades criminosas, contudo, questiona-se: quais medidas estão sendo adotadas pela Polícia Militar do Estado da Bahia, no que se diz respeito à capacitação e desenvolvimento de competências, sob o viés de práticas educacionais especializadas, tendo como modelo de gestão e ensino, a Unidade Operacional Especializada CIPE/Caatinga?

Ainda sobre esse ponto, consideremos a manifesta relação entre gestão, educação continuada e qualificação, tendo como foco a existência, a relevância e a realização de cursos específicos para a atuação policial em área de caatinga, sendo eles; o estágio de caatinga outrora oferecido pelo Núcleo de Instruções e Operações em Área de Caatinga - NIOPAC, não mais efetivo, e o Curso de Operações Rurais - COR, oferecido e coordenado pela própria CIPE/Caatinga.

Assim sendo, o presente artigo busca investigar e validar as práticas aprendidas e as melhorias apreendidas, no ambiente organizacional da CIPE/Caatinga, tendo em vista a 
qualificação de Profissionais de Segurança Pública, em meio à observância do VIII Curso de Operações Rurais. Nesse contexto, não nos caberá sinalizar a deficiência estrutural que é fornecida pelo estado, ente mantenedor, mas sim, de como podemos ressignificar as ferramentas organizacionais, a ponto de manter a referida Unidade Operacional Especializada - UOE como uma "tropa de elite" altamente qualificada, reconhecida pelo seu serviço de excelência e, principalmente, pronta para qualquer missão.

\section{Sob o ponto e vista organizacional}

Ao nos debruçarmos sobre o "desenvolvimento de competências", tema recorrente em inúmeros estudos nas áreas de gestão de empresas e recursos humanos, perpassamos por conceitos referentes ao clima e sinergia organizacionais, promoção de melhorias, motivação, retroalimentação, feedback e resultados, entre outros, contudo, e em se tratado de um ente da administração pública, pois devemos entender a Polícia Militar do Estado da Bahia como tal, raras ou poucas são as fontes e/ou estudos que lidam com a gestão de competências e práticas educacionais/instrucionais em ambientes Policiais Militares.

Vale salientar o termo instrucional, visto que tal implantação não somente depende/advém de uma demanda social e organizacional, mas estratégica e pedagógica também, fortalecido pela realização de estudos acerca da viabilidade, necessidade e aplicação de tais ferramentas de gestão. Entendamos que tudo o que se diz respeito à qualificação na Polícia Militar do Estado da Bahia, na figura do Instituto de Ensino e Pesquisa - IEP, transita e deve obrigatoriamente transitar, pelo exercício da andragogia/docência e gestão, justificando o seu caráter misto, além, é claro, da concretização em prol de uma finalidade.

Então, a fim de responder ao que o artigo se propõe, vamos vislumbrar o VIII Curso de Operações Rurais, e o percebamos como prática docente-gestacional genuína e originária da CIPE/Caatinga, que busca desenvolver, junto à sua tropa, a expertise necessária para o enfrentamento de situações policiais típicas e atípicas.

Em 2003, com vistas ao aperfeiçoamento técnico e tático da unidade, 2 (dois) Oficiais Policiais Militares, os então, $1^{\text {o }}$ Tenentes PM Ednaldo Siqueira Vieira e Henrique José Moreira Borri foram obter conhecimentos no Curso de Operaciones Especiales - COPES, na 
Polícia Nacional da Colômbia, e logo após a conclusão e retorno dos mesmos, fora formada a primeira turma do Curso de Operações Rurais - I COR, no mês de agosto do mesmo ano.

Por entender que a capacitação inicial, oriunda dos cursos de formações, não dá conta da multiface da prevenção e combate da violência em ambientes rurais, o I COR redesenhou a postura da unidade, não só pela qualificação técnica agora conhecida, percebida e oferecida aos primeiros "Guerreiros do Sol", mas pela significativa melhora no ambiente organizacional, e, consequentemente, no serviço especializado ofertada à população baiana. Relata-se, inclusive, que no ano de 2003, e de acordo com dados estatísticos da própria Polícia Militar do Estado da Bahia, a CPAC, atual CIPE/Caatinga, foi a unidade policial militar que mais apreendeu armas e drogas em todo o estado.

Por ora, e para que bem compreendamos, as Operações Rurais são aquelas desenvolvidas em ambientes rurais, face às características ambientais próprias, requerendo do Policial Militar, capacitações técnicas, táticas, mentais, físicas e psicológicas, específicas e condicionadas, em função do altíssimo grau de dificuldade, ora apresentada pelas contingências, pelas condições recursais, pela operação policial em si e/ou pela situação-crime em questão. Legitima-se aqui, a importância na relação entre o indivíduo, a instituição e a capacitação continuada, orientada ao desenvolvimento das competências exigidas para o profissional, realizada por Le Boterf, a saber:

O desenvolvimento de competências humanas depende essencialmente de três fatores: do interesse da pessoa por aprender; de um ambiente de trabalho que incentive a aprendizagem; e do sistema de educação corporativa disponível ao indivíduo. (1999, apud CARBONE e JUNIOR, 2009 p. 73)

O curso consiste na transmissão de conhecimentos específicos sobre técnicas e táticas policiais militares, individuais e coletivas, permitindo assim, a padronização de condutas e a consciente execução das Operações Rurais nos mais diversos biomas existentes no estado da Bahia.

Para tal propósito, o "in loco" dar-se-á na CIPE/Caatinga, através da cessão e do oferecimento constante de cursos e instruções, visando a capacitação e qualificação do seu corpo de encarregados de aplicação da lei, ao tempo que procura, essencialmente, enquanto promotora de práticas de gestão, ratificar a máxima de que quanto melhor qualificado, reconhecido e acompanhado o seu policial militar estiver, melhor será para a unidade em si, 
bem como ao produto final, que é o oferecimento do serviço policial especializado à comunidade.

\section{Sobre o VIII Curso de Operações Rurais}

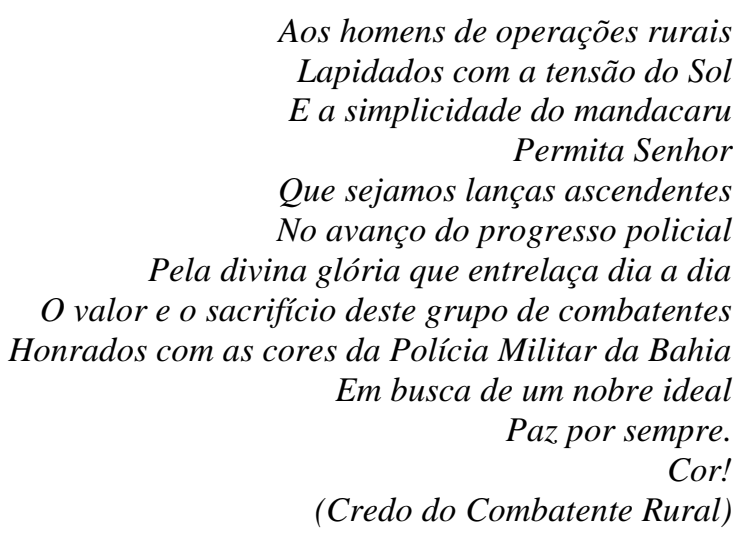

O Curso de Operações Rurais, Edição 2017, teve o seu início com a publicação do EDITAL N. ${ }^{\circ}$ IEP/CPCP, em 22 de Maio de 2017, sendo este regulado pela Portaria n. ${ }^{\circ} 040-$ CG/08, publicada no Boletim Geral Ostensivo - BGO n. ${ }^{\circ}$ 198, de 23 de outubro de 2008, alterada pela portaria $n^{\circ} 061-\mathrm{CG} / 11$, publicada no BGO n. ${ }^{\circ}$ 135, de 18 de julho de 2011, prescrevendo assim, procedimentos referentes à indicação de Policiais Militares candidatos aos cursos e estágios promovidos pela PMBA ou em outras instituições e dando outras providências, tornando público, no âmbito da PMBA, a abertura de inscrições, mediante

Tabela 01 - Distribuiçao dos Alunos do VIII COR

\begin{tabular}{c|c|c}
\hline POSTO/GRADUAÇÃO & QUANTIDADE & ORIGEM \\
\hline CAPITÃO (CAP) & 11 & 10 PMBA/01 PMPI (Piauí) \\
\hline TENENTE (TEN) & 11 & $\begin{array}{c}\text { P PMBA } \\
\text { PMCE (Ceará) } \\
\text { 01 PMPI }\end{array}$ \\
\hline SARGENTO (SGT) & 01 & PMBA \\
\hline CABO (CB) & 02 & 01 PMBA \\
\hline SOLDADO (SD) & 16 & PMBA \\
\hline
\end{tabular}




\begin{tabular}{c|c|c}
\hline AGENTE (APRF) & 01 & $\begin{array}{c}\text { POLICIA RODOVIARIA } \\
\text { FEDERAL (PRF) }\end{array}$ \\
\hline AGENTE (APF) & 01 & POLÍCIA FEDERAL \\
\hline AGENTE (APEN) & 01 & $\begin{array}{c}\text { DIRETORIA } \\
\text { PENITENCIÁRIA DE } \\
\text { OPERAÇÕES ESPECIAIS - } \\
\text { SSP/DF }\end{array}$ \\
\hline
\end{tabular}

Fonte: IEP/PMBA

Após as indicações, iniciam-se as fases eliminatórias, algo que nessa edição se deu num período de 40 (quarenta) dias, sendo compostas por avaliações médica, física e psicológica, bem como a entrevista, onde são coletadas informações diversas e cruciais que auxiliarão o Núcleo de Instrução - NI na condução do curso.

Todas as fases são devidamente acompanhadas e analisadas pelo Instituto de Pesquisa e Ensino, atribuindo ao curso uma estrutura científica e ordenada, pois, entende-se que cada evento proposto, cujo objetivo é a capacitação, serve não só como multiplicador de conhecimento, mas também, como laboratórios para análises e melhorias.

A ideia de educação continuada ganha outra roupagem, e diríamos até, outra nomenclatura, no que se diz respeito à seara Policial Militar, pois, como dito anteriormente, o ensinar, com o viés docente/pedagógico, traduz-se agora em capacitar, treinar, multiplicar, especializar, mas em suma, possuem o mesmo direcionamento.

Ao longo dos 21 (vinte e um) dias de curso, os alunos são submetidos à inúmeras situações-problemas, onde são exigidas competências e habilidades físicas, técnicas, intelectuais, mentais, relacionais, dentre outras, a fim de construir o conhecimento adequado para ambientá-los e adequá-los à doutrina de ação de um Policial Operador Rural. Para tanto, entende-se que a Doutrina das Operações Rurais é aquela baseada nos preceitos, princípios e valores policiais militares, visando habilitar o policial, mediante o trinômio de operar, treinar e dar treinamento, a intervir em situações críticas em ambientes rurais, utilizando-se para isso, de procedimentos, treinamentos, táticas, técnicas, armamentos e equipamentos específicos, a qualquer hora do dia ou da noite, sob quaisquer circunstâncias, tendo por objetivo, solucionar de forma ética, técnica, legal e aceitável, as ocorrências policiais que assim surgirem.

Diante desse teatro de situações, devidamente controlado, desenvolve-se a vontade de superação dos alunos, na medida em que a solidariedade, traduzida em união e integração, 
gera o "espírito de corpo", jargão militar que denota "conectá-los entre si, ajudando uns aos outros, em busca de um objetivo comum". Nesse contexto, onde todos são números, as patentes são esquecidas, e o conceito de "turno", entendido como grupo/conjunto, prevalece, tomando corpo, fortalecendo os laços, as relações e os objetivos.

As Operações Rurais exigem conhecimentos específicos, algo já pontuado ao longo desse artigo, mas além do aspecto técnico, também visam o desenvolvimento pessoal, ao estimular e submeter o Policial Militar a pensar e agir, assertivamente, sob circunstâncias adversas. O Operador Rural, antes de qualquer coisa, deve ter plena noção da sua capacidade intelectual, mediante análise, síntese, ação e direcionamento daquilo que lhe será proposto, seja durante o curso, seja no dia-a-dia policial.

E então, a Fazenda COR, também conhecida como Fazenda Mandacaru, situada no Distrito de Barra do Tarrachil, município de Chorrochó-BA, estabelece-se como a grande sala de aula. A mesma dista 330 (trezentos e trinta) km de Juazeiro-BA, e está situada no extremo norte do estado da Bahia, limítrofe com o "Polígono da Maconha" em Pernambuco. Além das características típicas da mata branca, no que concerne à fauna e flora, e da proximidade com o Rio São Francisco, é lá que se encontra a Base Operacional da CIPE/Caatinga, denominada Base Frade, de onde são coordenadas todas as ações das equipes de serviço, fazendo com que os discentes percebam a estrutura, não só a nível operacional, mas a nível tático, e por vezes, estratégico.

\section{Sobre a metodologia e os aspectos pedagógicos do VIII Curso de Operações Rurais}

A metodologia do VIII Curso de Operações Rurais se deu através de aulas expositivas, dos mais diversos assuntos, com as prescrições contidas no plano de curso especifico e demais normas, estabelecidas pelo Instituto de Ensino e Pesquisa da PMBA. As instruções são, prioritariamente, atividades práticas, com aulas teóricas em sala de aula, quando aplicáveis, através de técnicas e métodos individualizados e em grupo, com simulações de situações reais, visando alcançar os objetivos propostos pelo curso, que são:

1. Qualificar e preparar Policiais Militares do Estado da Bahia para a atuação, emprego e execução de ações e operações em áreas rurais, nos biomas caatinga, cerrado e mata atlântica; 
2. Formação de multiplicadores, pois, tal preparação o qualifica também para a transmissão desses conhecimentos aos Policiais Militares pertencentes às Unidades Ostensivas de Policiamento da área de atuação da Unidade Ostensiva Especializada ou do bioma predominante, aumentando assim, o preparo técnico-profissional, a capacidade de atuação e a autoestima dos Policiais empregados, retroalimentando os conhecimentos sobre o assunto.

Para um proveitoso aprendizado e, por consequência, eficiente captação das matérias elencadas e trabalhadas durante o curso, o número de alunos não deverá exceder o limite de 40 (quarenta) por turma. O curso possuiu carga horária de 160 (cento e sessenta) horas/aula, e foram distribuídas em um período letivo de 21 (dezesseis) dias, em turnos compatíveis com a exploração do perfil de cada conteúdo especifico de disciplinas e atividades.

Tabela 02 - Disciplinas do VIII COR

\begin{tabular}{|c|c|c|c|}
\hline $\mathbf{N}^{\mathbf{0}}$ & DISCIPLINAS & CLASSIFICAÇÃO & C. HORÁRIA \\
\hline 1 & Doutrina Organizacional & Teórica & $10 \mathrm{H} / \mathrm{A}$ \\
\hline 2 & Instrução Tática Individual & Prática & $10 \mathrm{H} / \mathrm{A}$ \\
\hline 3 & Atendimento Pré-hospitalar em Área Conflagrada & Teórico-Prática & $10 \mathrm{H} / \mathrm{A}$ \\
\hline 4 & Técnicas de Orientação e Navegação & Teórico-Prática & $10 \mathrm{H} / \mathrm{A}$ \\
\hline 5 & Técnicas verticais e transposição de obstáculo & Prática & $10 \mathrm{H} / \mathrm{A}$ \\
\hline 6 & Técnicas de Patrulha Policiais Militares & Teórico-Prática & $20 \mathrm{H} / \mathrm{A}$ \\
\hline 7 & Armamento, Tiro Tático e Tiro de Combate & Teórico-Prática & $16 \mathrm{H} / \mathrm{A}$ \\
\hline 8 & Táticas e Técnicas de Combate Rural & Prática & $10 \mathrm{H} / \mathrm{A}$ \\
\hline 9 & Técnicas em Estabelecimento Prisional & Teórico-Prática & $10 \mathrm{H} / \mathrm{A}$ \\
\hline 10 & Técnicas de Operações Ribeirinhas & Teórico-Prática & $10 \mathrm{H} / \mathrm{A}$ \\
\hline 11 & Técnicas de Sobrevivência no Bioma & Teórico-Prática & $10 \mathrm{H} / \mathrm{A}$ \\
\hline 12 & Técnicas de Rastreamento e Contra Rastreamento & Teórico-Prática & $10 \mathrm{H} / \mathrm{A}$ \\
\hline 13 & Exercício Simulado de Sobrevivência no Bioma & Prática & $24 \mathrm{H} / \mathrm{A}$ \\
\hline Total & & $160 \mathrm{H} / \mathrm{A}$ \\
\hline TOTAL GERAL & 160 H/A \\
\hline
\end{tabular}

Fonte: CIPE/CAATINGA - PMBA

O Comandante da Unidade Operacional Especializada onde o curso estiver sendo realizado, assume a função de coordenador, neste caso, ao Major PM Comandante da CIPE/Caatinga coube nomear seus auxiliares, remetendo tal relação ao Comando de 
Policiamento Especializado - CPE que, por vez, providenciou a devida publicação em Boletim Geral Ostensivo.

Para esta edição, foram convocados 4 (quatro) Policiais Militares para compor o Núcleo de Instrução - NI, sendo 1 (um) coordenador e 3 (três) auxiliares, que em conjunto com a Equipe Médica da própria PMBA, acompanhou o curso diuturnamente, além dos instrutores e monitores das disciplinas específicas, conforme tabela a seguir:

Tabela 03 - Relação das Disciplinas e seus Instrutores/Monitores do VIII COR

\begin{tabular}{|c|c|c|}
\hline $\mathbf{N}^{\mathbf{0}}$ & DISCIPLINAS & INSTRUTORES E MONITORES \\
\hline 1 & Instrução Tática Individual & $01 \mathrm{ST} / 01 \mathrm{SGT} / 01 \mathrm{CB}$ \\
\hline 2 & Atendimento Pré-Hospitalar & 01 CAP/01 SGT \\
\hline 3 & Orientação e Navegação & $01 \mathrm{ST} / 01 \mathrm{SD}$ \\
\hline 4 & Armamento & 02 CB/01 SGT/01 SD \\
\hline 5 & Técnicas de Sobrevivência & $02 \mathrm{CB} / 01 \mathrm{SGT} / 01 \mathrm{SD}$ \\
\hline 6 & Ofidismo & PROFESSOR CIVIL \\
\hline 7 & Patrulha Rural/Combate Rural & $01 \mathrm{MAJ} / 01 \mathrm{ST} / 02 \mathrm{CB}$ \\
\hline 8 & Rastreamento e Contra Rastreamento & 01 CAP PMPE/02 SD PMPE \\
\hline 9 & Agentes Químicos & $01 \mathrm{TEN} / 01 \mathrm{SGT}$ \\
\hline 10 & Técnicas Verticais & 01 TC BMBA \\
\hline 11 & Ações de Choque & $01 \mathrm{CAP} / 01 \mathrm{TEN} / 01 \mathrm{SGT}$ \\
\hline 12 & Operações Ribeirinhas & $1^{a}$ CIA DE INFANTARIA EB + EQUIPE DE INSTRUÇÃO \\
\hline 13 & Intervenções Prisionais & $01 \mathrm{CAP} / 01 \mathrm{SGT}$ \\
\hline 14 & Patrulha Urbana & $01 \mathrm{ST} / 01 \mathrm{CB} / 01 \mathrm{SD}$ \\
\hline 15 & Fogo em Movimento Rural & $01 \mathrm{MAJ} / 01 \mathrm{ST} / 02 \mathrm{CB} / 02 \mathrm{SD}$ \\
\hline 16 & Entorpecentes & $01 \mathrm{CAP}$ \\
\hline 17 & Tiro Noturno & $01 \mathrm{SGT} / 01 \mathrm{SGT} / 01 \mathrm{CB}$ \\
\hline 18 & Abate de Víveres/Sobrevivências & $01 \mathrm{SGT} / 02 \mathrm{SD}$ \\
\hline 19 & Primeira Resposta com Explosivos & 01 CAP/01 SGT \\
\hline 20 & Acuidade Auditiva e Visual & $01 \mathrm{TEN} / 01 \mathrm{ST} / 01 \mathrm{SGT} / 01 \mathrm{CB} / 01 \mathrm{SD}$ \\
\hline
\end{tabular}

Fonte: CIPE/CAATINGA - PMBA 
Sobre o quadro acima, onde se leem, MAJ e ST, entendem-se, respectivamente, por Major e Subtenente.

Salienta-se que são de inteira responsabilidade do coordenador e de seus auxiliares, a manutenção e a observância da disciplina e do cumprimento das normas (contidas no manual do aluno) durante o transcorrer do curso, devendo adotar as providencias legais de acordo com o caso que, por ventura, venha a acontecer. Dentre outras atribuições pedagógicas, caberá também ao Núcleo de Instrução - NI, o seguinte: cumprir fielmente as normas previstas no tocante à apresentação do plano de aula, supervisionar a extensão da carga horária, subsidiar a aplicação dos conteúdos e avaliações por parte dos instrutores e monitores, manutenir os registros e notas dos alunos, confeccionar documentos próprios, planilhas, atas e, ao final, realizar a solenidade de conclusão do VIII Curso de Operações Rurais.

\section{Avaliação}

A avaliação do corpo discente consiste na medição dos rendimentos nas disciplinas e atividades, através de um processo contínuo, por meio de verificações escritas para as disciplinas teóricas e da observação do desempenho do instruendo nas atividades práticas, ambas ocorrendo, imediatamente, após o término da instrução. Durante o período do curso, observa-se também o desenvolvimento pessoal e profissional do aluno, onde se constituem baremas, de acordo com a especificidade de cada atividade, qualificados como "Fatos Observados Positivos e Negativos", que terão valor especifico, sendo ao final, obtida a média, com a consequente conceituação e classificação no curso.

Para a aprovação no COR, o instruendo deverá obter, no mínimo, média final 6,0 (seis) e não ter sido reprovado em nenhuma disciplina ou atividade. A reprovação em qualquer uma das disciplinas ou atividades ensejará o julgamento por parte do Conselho do curso, que deliberará sobre a permanência ou desligamento do aluno. A reprovação do instruendo em qualquer disciplina ou atividade, bem como a impossibilidade de realização de qualquer verificação por problemas físicos, de saúde ou outro que venha a culminar com a não realização da verificação, será o discente, imediatamente, desligado do COR, sendo o fato registrado em ata final de curso. 
Percebe-se uma rígida preocupação com os critérios de avaliação, visto que a realização de tal curso é conduzida, organizacionalmente, como uma especialização, e, por essa lógica, há uma bagagem pedagógica bem robusta para validar o processo de ensinoaprendizagem. Todos aqueles empregados no curso, seja na condição de coordenador, auxiliar, instrutor e/ou monitor, deverão ter, no mínimo, a referida qualificação, bem como, experiência policial enquanto operador rural.

Após a primeira semana de curso, dos 44 (quarenta e quatro) Policiais-Alunos inscritos, 20 (vinte) haviam sido eliminados por não cumprirem alguma das etapas propostas durante o curso. Os 24 (vinte e quatro) alunos restantes seguiram e concluíram o curso no dia 14 de Julho de 2017, conforme descrito abaixo.

Tabela 04 - Relação dos Concuintes por Postos, Graduações e Funções do VIII COR

\begin{tabular}{|c|c|c|}
\hline $\mathrm{N}^{\circ}$ & \multicolumn{2}{|c|}{ CONCLUÍNTES DO VIII COR } \\
\hline 1 & 21 POLICIAIS MILITARES & 05 CAP/08 TEN/02 SGT/06 SD \\
\hline 2 & 03 AGENTES POLICIAIS & 01 APF/01 PRF/01 APEN \\
\hline
\end{tabular}

Fonte: CIPE/CAATINGA - PMBA

\section{Considerações Finais}

SENHOR!

Vós que fostes sábio ao criar os rios e os mares Pareceis ter esquecido do nosso sertão Vós que destes aos homens

A terra para dela tudo tirar Não nos destes a mesma sorte Porém hoje, oh deus Vejo quão generoso fostes A nós guerreiros de caatinga Deste-nos a resistência ao sol A sapiência para da natureza tudo aproveitar A força de vontade para continuar a lutar

E ante o inimigo jamais recuar Obrigado, Senhor Deus,

Porque criastes um ambiente Onde um ser humano comum não possa sobreviver Pois só os perseverantes E os fortes de espírito aqui conseguem lutar. (Oração do Guerreiro de Caatinga) 
Durante os 21 (vinte e um) dias do VIII Curso de Operações Rurais e as semanas subsequentes, observamos que os policiais instruendos e instrutores, bem como aos policiais pertencentes ao quadro operacional e administrativo da CIPE/Caatinga, estavam em perfeita sinergia, pois, todos respiravam a mesma ideia, o mesmo direcionamento organizacional, não só reforçado pelo senso de pertencimento, mas com a consciência da relevância do quão importantes foram os ensinamentos. "Algo mudou para melhor" era essa a expressão obtida após conversarmos com alguns dos alunos envolvidos no curso.

O VIII Curso de Operações Rurais é uma ação pedagógica a nível de especialização policial-militar, e as ferramentas utilizadas para esta formação são voltadas para a gestão (capacitação/treinamento) e para o desenvolvimento de competências.

A PMBA é uma organização tradicional, por isso, cada vez mais, surge a necessidade de reavaliação da formação e da prática policial, e, sobretudo uma mudança na cultura organizacional desta instituição que possibilite a formação um sistema de segurança pública mais próximo do ideal para a realidade brasileira. (GONDIM e SOUZA, 2017, p. 22)

Toda a estrutura encabeçada e designada pelo Instituto de Ensino e Pesquisa, desde o envio de projeto prévio, com uma justificativa devida para a consecução do processo, em conjunto com os esforços dos Departamentos Médico e de Desporto, em consonância, inclusive, com a reestruturação sistêmica e organizacional da própria instituição, focando nas gestões de processo, projetos, recursos humanos e desenvolvimento de competências, estabelece não só um adequado direcionamento do curso, mas também ressignifica a importância dada à capacitação do profissional de segurança pública.

Importante salientar que o curso de Operações Rurais, no que se diz respeito ao policiamento especializado, representa um marco na prevenção e repressão da violência, através do processo de ensino-aprendizagem, se constituindo em um grande exercício de docência e gestão, mesclando perfeitamente essas duas facetas. Como consequência, gera uma sólida ideia de conhecimento trabalhado e contínuo que, ao ser transmitido de forma metodologicamente adequada, consubstancia a gestão da CIPE/Caatinga.

O Major PM Comandante da CIPE/Caatinga tem plena consciência da importância do curso, tanto que nos relatou que a "educação continuada", através de instruções específicas e constantes, cursos e estágios, e a promoção de recursos para que o seu Policial Militar possa melhor operar, são pontos importantes do seu modelo de gestão. Contudo, paralela à essa importância atribuída, destacou, com base na experiência adquirida após conduzir 3 (três) 
edições do referido curso, não só a necessidade da continuidade, sob escopo da presente capacitação policial militar, mas também, a ampliação de 21 (vinte e um) para 30 (trinta) dias ou mais, tendo em vista a compressão do tempo, os imprevistos, a instância em aprofundar-se nas disciplinas já existentes e implantar outras disciplinas específicas e relacionadas às Operações Rurais, e uma maior disponibilidade para simulações e atividades práticas. Em seu entendimento, tais medidas favoreceriam uma prática pedagógica mais completa.

Por fim, validamos que a experiência do VIII Curso de Operações Rurais, através do paralelo entre gestão e educação, não só tende a capacitar e a beneficiar o clima organizacional, mas reflete, substancialmente, em três outros pontos: na valorização do Profissional Policial Militar, na busca organizacional pela qualidade contínua, e num qualificado serviço especializado oferecido à sociedade por parte da CIPE/Caatinga, e nesse último aspecto, entende-se que quanto mais motivado e capacitado o Policial Militar estiver, melhor será o retorno à sociedade, e melhor será o efetivo cumprimento do dever policial, valendo-se, principalmente, da segurança na ação decorrente do conhecimento agregado e apreendido pelo Policial Militar, corroborando com o que afirma Brandão e Babry,

A aplicação de conhecimentos, habilidades e atitudes no trabalho, gera um desempenho profissional, o qual, por sua vez é expresso pelos comportamentos que a pessoa manifesta e pelas consequências desses comportamentos, em termos de realizações e resultados. O desempenho da pessoa representa, então, uma expressão de suas consequências. (BRANDÃO e BABRY, 2005, p.181)

Impressões, mediante conversas informais e observações casuais, junto aos policiais instruendos e instrutores, acerca do significado em participar do VIII Curso de Operações Rurais, antes e após a conclusão do curso, bem como aos policiais pertencentes aos quadros operacional e administrativo da CIPE/Caatinga, confirmam, mesmo que empiricamente, a melhora do clima organizacional, promovida pelo rejuvenescimento do ambiente de trabalho, dada a concretização do evento. E até mesmo sob o viés operacional, tendo como parâmetro a produtividade policial, ou seja, o números de ocorrências policiais com intervenções das Equipes da CIPE/Caatinga, verificou-se um aumento bastante significativo. 


\section{Referência}

BERGAMINI, Cecília W. Motivação nas Organizações. 4. Ed. São Paulo: Atlas, 1997.

BRANDÃO, H. P.; BAHRY, C. P. Gestão por competências: métodos e técnicas para mapeamento de competências. Revista do Serviço Público, v. 56, n. 2, p. 179-194, 2005.

CARBONE, Pedro Paulo; JUNIOR, Edgard Rufatto. O sistema de desenvolvimento profissional e de gestão por competências do Banco do Brasil. Disponível em: http://www.educor.desenvolvimento.gov.br/public/arquivo/arq1229429519.pdf, acessado em 24/11/2017.

GONDIM, Regia Cristina Freitas e SOUZA, Nadjane Gonçalves de. Ronda Maria da Penha: mudança na cultura organizacional. 2017.

LUZ, Ricardo. Gestão do Clima Organizacional. Rio de Janeiro: Qualitymark, 2003.

LIBÂNEO, J. C. Didática. São Paulo: Cortez, 1994.

LIKERT, Rensis. Novos Padrões de Administração. 2. Ed. São Paulo: Pioneira, 1979.

MIZUKAMI, M. G. N. Ensino: As Abordagens do Processo. São Paulo: EPU, 1986.

PMBA, Edital N. ${ }^{\circ}$ IEP/CPCP - 022/05/2017. Disponível em http://intranet.pm.ba.gov.br/, acessado em: 28/08/2017.

PMBA, Portaria n. ${ }^{\circ}$ 040-CG/08, publicada no BGO n. ${ }^{\circ} 198$ de 23 de outubro de 2008. Disponível em http://intranet.pm.ba.gov.br/, acessado em: 01/10/2017.

PMBA, Projeto VIII COR 2017. IEP. Juazeiro. 2017.

PMBA, Hinário do VIII Curso de Operações Rurais. IEP. Juazeiro: Edição Única, 2017.

PMBA, Manual do Aluno do VIII Curso de Operações Rurais. IEP. Juazeiro: Edição Única, 2017.

PMBA, Revista Organizacional Comemorativa de 10 Anos da CIPE/Caatinga. Juazeiro: Edição Única, 2011.

PMBA, Revista Organizacional Comemorativa de 15 Anos da CIPE/Caatinga. Juazeiro: Edição Única, 2016. 
PONCIONI, P. Tendências e Desafios na Formação Profissional do Policial no Brasil. Revista Brasileira de Segurança Pública, São Paulo, ano 1, edição 1, 2007.

SOUZA L. R. A Formação do Educador Policial Militar. PUC de São Paulo. Disponível em http://www.uninove.br/PublishingImages/Mestrados\%20e\%20Doutorados/edu/I\%20se minario/MPF\%2026.pdf, acessado em 05/20/2017.

TZU, Sun. A Arte da Guerra. São Paulo: Conrad Editora do Brasil, 2006.

\section{Como citar este artigo (Formato ABNT):}

SILVA, Gilmar S.; DUARTE, Stênio F.P.; GOMES, valquíria S.; MACEDO, Aparecida S. S. Avaliação da influência de transtornos mentais sobre a pressão arterial em idosos cadastrado em um projeto. Id on Line Revista ultidisciplinar e de Psicologia, 2018, vol.12, n.39, p.246-261. ISSN: 1981-1179.

Recebido: 12.11 .2017

Aceito: 25.11.2017 